\title{
ANABOLIZANTES: ENTRE OS LIMITES DO FAIR PLAY, DA ESTÉTICA E DO CRIME
}

\section{ANABOLIC STEROIDS: BETWEEN THE LIMITS OF THE FAIR PLAY, THE AESTHETICS AND THE CRIME}

Joedson de Souza Delgado'

Ivo Teixeira Gico Júnior²

\begin{abstract}
RESUMO: No presente trabalho analisa-se o abuso de esteroides anabólico-androgênicos sob a perspectiva jurídico-penal. Utilizando uma metodologia dedutiva, e com análise de posicionamentos doutrinários, jurisprudenciais e de dispositivos legais, verificouse que o doping nos esportes como uma forma de melhorar as habilidades físicas em busca de fama e bem-estar encontrou a antiga obsessâo humana de conseguir uma imagem corporal mais atraente. Daí, portanto, o declínio de determinada incriminaçâo sobre alguns comportamentos em nome dos princípios fundamentais do direito penal.
\end{abstract}

Palavras-Chave: Anabolizantes;estética;medicina esportiva;doping nos esportes; responsabilidade penal.

ABSTRACT: The present study analyzes the abuse of anabolic-androgenic steroids from a legal penal perspective. Using a deductive methodology, and with analysis of doctrinal, jurisprudential and legal dispositions, it was verified that doping in sports as a way to improve physical abilities in search of fame and well-being found the ancient human obsession of achieving a more attractive body image. Hence, therefore, the decline in certain criminal acts on some behaviors on behalf of the fundamental principles of criminal law.

Keywords: Anabolic steroids;aesthetics;sports medicine;doping in sports; criminal liability.

1 Mestre em Direito pelo Centro Universitário de Brasília - UniCEUB. Especialista em Direito Sanitário pela Fundaçăo Oswaldo Cruz - Fiocruz e em Direito Administrativo pelo Instituto Brasiliense de Direito Público - IDP. Bacharel em Administraçăo pela Universidade de Brasília - UnB e em Direito pelo Centro Universitário do Distrito Federal - UDF. Servidor público na Agência Nacional de Vigilância Sanitária Anvisa.joedson.delgado@hotmail.com

2 Doutor em Direito pela Universidade de Sáo Paulo - USP e em Economia pela Universidade de Brasília - UnB. Mestre com honra máxima em Direito pela Columbia University in the City of New York, EUA. Bacharel em Direito pela Universidade de Brasília - UnB. Professor do Programa de Pós-Graduaçáo em Direito do Centro Universitário de Brasília - UniCEUB. Advogado.gico@ghdadvogados.com.br 


\section{INTRODUÇÃO}

Nos últimos tempos tem se intensificado o consumo de esteroides anabólico -androgênicos (EAAs, ou AAS - anabolic androgenic steroids -,em inglês),vulgarmente conhecidos como anabolizantes,e popularmente como "bomba". Na definiçăo de Camilo e Furtado (2017, p. 35), os EAAs sâo substâncias farmacológicas ergogênicas para aumento de eficiência, energia e potência do organismo com o objetivo de alcançar melhores resultados em competiçōes esportivas de alto nível ao sobrepujar as fadigas.

A maioria dos usuários de EAAs age motivada pelo anseio de melhorar sua aparência física(massa muscular) e alcançar a vitória nos esportes (força, potência e velocidade muscular). Com efeito, a autonomia do indivíduo coloca-se em xeque dadas as circunstâncias de vulnerabilidade,já que os atalhos săo deletérios e podem causar adiçấo e dependência comportamental.

Com isso, com o presente artigo objetiva-se analisar a questăo do abuso de esteroides anabólico-androgênicos sob a perspectiva jurídica-penal. No que tange ao objetivo, apresenta-se a importância do problema da dopagem bioquímica que aqui será abordado em caráter interdisciplinar, pois é um assunto de interesse năo somente da medicina do esporte, mas também das ciências jurídicas pelas posiçôes doutrinárias.

Justamente por isso, deve-se refletir sobre as consequências sancionatórias de cunho administrativo pelas instituiçóes competentes e de reproche social, as mesmas que - fora do esporte - consentem e cultuam as substâncias que amplifiquem a força, mesmo que transitoriamente, e ressaltem a beleza de um corpo atlético, mas que sâo passíveis de serem tolhidas sobre qual bem jurídico o direito penal quer atuar.

No desenvolvimento deste texto foi utilizada a pesquisa exploratória de abordagem dedutiva que evoluiu aos leading cases que oscilam no entendimento quanto à possível responsabilidade penal do uso de EAAs nos esportes de lazer incluindo a possível culpa de outras pessoas que possam participar no processo de transaçấo comercial dos referidos fármacos.

Para alcançar o objetivo proposto procedeu-se a revisáo de literatura com pesquisa realizada no sítio eletrônico dos cinco tribunais regionais federais, e nas cortes superiores foram encontrados dados sobre a temática EAAs voltados para os aspectos processuais: revogaçâo de prisăo cautelar, competência de julgamento por tribunal federal ou estadual, trancamento de açăo penal, apreensăo de medicamentos, entre outros (BRASIL, 2000, 2010b, 2013, 2015b).

Assim, questiona-se: é acertado o reproche penal à prática do doping desportivo adotado pelo legislador pátrio?

No primeiro capítulo, săo analisados os EAAs e seus efeitos sobre o corpo. No segundo, discorre-se sobre a prevalência e a incidência do uso dos EAAs e a forma de sua obtençăo. No terceiro capítulo, é brevemente discutida a experiência jurídica norte-americana sobre os EAAs. No quarto, analisa-se o tratamento jurídico-penal dos EAAs no Brasil. Ao final, responde-se ao problema de pesquisa proposto. 
Esse tema é particularmente importante, tendo em vista os diversos contextos em que os EAAs se inserem, a fim de resolver juridicamente os eventos tangíveis da complexa vida contemporânea em matéria de esporte e saúde pública.

\section{OS EAAS E SEUS EFEITOS SOBRE O CORPO}

Os esteroides anabolizantes sâo substâncias industrializadas imitativas de certos hormônios naturais do organismo, notadamente, drogas derivadas do hormônio sexual masculino, a testosterona, que regulam e controlam a maneira como o corpo humano funciona e se desenvolve. Palermo-Neto (2018, p. 623) descreve que a palavra anabolizante deriva de "anabolismo" referindo-se a um "[...] conjunto de processos fisiológicos que resultam na fixaçăo de nutrientes e, consequentemente, na formaçăo e no crescimento dos tecidos."

Por seu turno, os esteroides imitam os efeitos de testosterona no corpo ao estimularem os feixes de células musculares e miócitos para produzirem proteínas a um ritmo mais acelerado. Logo, os esteroides anabólicos elevam o acúmulo do nitrogênio proteico e năo proteico existente nos alimentos e sua consecutiva modificaçăo em proteína para os músculos esqueléticos.

Os principais EAAs secretados no organismo sâo os androgênicos e os corticoides (MACHADO; RIBEIRO, 2004). Os corticoides săo usados para fins terapêuticos em um número significativo de doenças, incluindo a artrite e a inflamaçăo resultante de uma lesăo, a exemplo dos princípios ativos: acetato de prednisolona, acetato de cortisona, dipropionato de beclometasona, budesonida, dexametasona, entre outros. Estes nâo sâo usados para promover a força dinâmica e aumentar a massa corporal magra.

Os androgênicos permitem o desenvolvimento físico de características sexuais masculinas ligadas ao efeito anabólico de construir tecido muscular alavancado pelo regime extenuante de exercícios físicos aliado à alimentaçăo balanceada. Nesse particular, a juventude é a faixa etária mais suscetível ao consumo de EAAs e ao descomedimento de suplementos alimentares em razáo do ímpeto pelo aumento e definiçấo de massa muscular a qualquer custo e pela falta de compreensáo quanto às vantagens e agravos desses produtos (NEUMARK-SZTAINER et al., 1999, p. 44; SILVA; LIMA, 2007, pp. 145-146).

É importante salientar que os EAAs nâo têm correlaçâo ou se confundem com suplementos de proteínas, carboidratos e aminoácidos para atletas e desportistas, todavia, Elliot e Goldberg (1996, p. 47) asseveram que tais componentes podem ser uma porta de entrada para seu uso ou para seu consumo ser ainda maior.

Insta registrar que os androgênicos săo: androstanolona, bolasterona, boldenona, cloroxomesterona, clostebol, deidroclormetil testosterona, drostanolona, estanolona, estanozolol, etilestrenol, fluoximesterona ou fluoximetil testosterona, formebolona, mesterolona, metandienona, metandranona, metandriol, metenolona, metiltestosterona, mibolerona, nandrolona, noretandrolona, oxandrolona, oximesterona, oximetolona, prasterona (deidroepiandrosterona - DHEA), somatropina (hormônio do crescimento humano), testosterona e trembolona, incluindo seus sais, éteres, ésteres e isômeros. A propósito, tais substâncias se encontram na lista "C5" da Portaria n. 344, de 12 de maio de 1998 da antiga Secretaria de Vigilância Nacional do Ministério da Saúde, 
ora atualizada pela Resoluçâo da Diretoria Colegiada - RDC n. 36, de 03 de agosto de 2011 (AGÊNCIA NACIONAL DE VIGILÂNCIA SANITÁRIA, 2011).

O objetivo comercial da síntese dos EAAs consiste nos esforços científicos para separar os efeitos androgênico-anabólicos da testosterona, no intuito de se criar substância de efeito apenas anabólico ou diminuta açăo androgênica com máxima capacidade anabolizante. Sobre a sintetizaçăo dos EAAs, Santos (2003, p. 4) assevera que:

[...] foram desenvolvidos primeiramente na década de 1930. Os alemăes experimentaram inicialmente em cáes e, depois, em seus próprios soldados na Segunda Guerra Mundial. Usaram ainda em seus prisioneiros, no intuito de mantêlos saudáveis, porque sofriam de má nutriçăo significativa.

Os EAAs sáo usados na medicina para o tratamento/controle de certas patologias, mas acabaram se transmutando para fins de ostentaçâo social e/ou estéticos e, em doses suprafisiológicas, podem levar a uma série de efeitos colaterais graves - por vezes irreversíveis aos órgáos e sistemas. Assim, o uso năo médico dessas drogas acarreta incontáveis riscos psicológicos e físicos (IP et al., 2012, pp. 916-918).

De maneira geral, Abrahin e Sousa (2013, p. 669-679) citam os danos que os EAAs podem provocar ao fígado, além das patologias cardiovasculares e da elevaçấo da pressâo arterial concomitante aos níveis de colesterol. Nos homens, podem acarretar o surgimento de algumas características femininas, como a ginecomastia (desenvolvimento de mamas), estrias e demais distúrbios, como impotência, infertilidade, aumento da próstata, atrofia testicular e retençăo hídrica. Já as mulheres podem incorporar algumas características masculinas secundárias, como voz grossa, aceleramento da calvície genética, atrofia das mamas, clitóris aumentado e hirsutismo (presença de pelos terminais), além de outras alteraçóes, como menstruaçăo irregular e alteraçôes na libido. Nos adolescentes, pode resultar em acne, estanque do crescimento, puberdade precoce, hipervirilizaçăo, entre outras patologias.

Kanayama et al.(2009, p. 1968-1970) e Greydanus e Patel (2002, pp. 830-833) realizaram estudos epidemiológicos nos Estados Unidos, nos países britânicos e nos países escandinavos, e relataram que os EAAs săo utilizados por 3 a $12 \%$ dos adolescentes homens. A porcentagem de usuárias de esteroides varia de 0,5 a 2,5\%, uma vez que estăo menos propensas a um corpo musculoso e, também, por estarem vulneráveis aos efeitos masculinizantes.

Por outro lado, o uso indiscriminado dos EAAs pode conduzir a certos distúrbios psíquicos, como depressấo, manias, agressividade e irritabilidade. Pope Júnior e Katz (1994, p. 377) realizaram um extenso estudo com 160 atletas do sexo masculino com doses elevadas de testosterona ( $-600 \mathrm{mg} /$ semana) e mostraram que $23 \%$ deles podem apresentar psicopatologias como dismorfia muscular (distúrbio da imagem corporal) e transtorno de ansiedade em frequência maior do que os nâo usuários.

O interesse pelos EAAs segue uma conduta sazonal motivada pela exibiçăo simbólica do corpo, que se inicia no período de verăo coincidente com a alta temporada de férias, de novembro a janeiro (MORAES, 2015, p. 2000). De qualquer forma, o uso dessas substâncias, aliado ao desejo de arquitetar o corpo, pode trazer consequências que impactam sobre o equilíbrio natural de hormônios, oferecendo, assim, diversos riscos que possibilitam a morte. 


\section{EAAS: USO E SUA OBTENÇÃO}

Este capítulo subdivide-se em duas partes. Na primeira, aborda-se a preponderância e a ocorrênciado uso de EAAs. Na segunda, adentram-se as formas de obtençâo da substância. A tônica dos EAAs, de modo geral, perfaz-se em ausência de controle de venda e consumo (comércio eletrônico irregular, falta de esclarecimentos dos riscos ao consumidor e limitada capacidade de análise dos produtos).

\subsection{A PREVALÊNCIA E INCIDÊNCIA DE USO DE EAAS}

Remontam à história variadas formas para aumentar a força física e melhorar o desempenho nos esportes, entretanto o uso de EAAs começou na segunda metade do século XX. Estima-se que o uso dessas substâncias por atletas e desportistas se difundiu no círculo de homens jovens em busca de uma percepçăo positiva de si mesmo.

Tavares (2002, p. 42) explica que tal comportamento

Seja no oriente, seja no ocidente, em sociedades simples ou complexas, a utilizaçăo de algum artifício (físico, químico, psicológico) destinado a aumentar as capacidades físicas humanas parece de tal forma presente que, penso, teríamos poucas dificuldades em classificá-los como um universal cultural.

Os protótipos de beleza subjacente podem compartilhar várias características, endossados pelos meios de comunicaçâo. Com a pressáo de ter uma imagem corporal atraente, em regra, as mulheres apontam a magreza, enquanto os homens, o desenvolvimento muscular.

Mundialmente, os EAAs săo utilizados em vários esportes, como fisiculturismo, atletismo, halterofilismo, nataçăo e ciclismo.

Na Olimpíada de 1988, em Seul, Coreia do Sul foram descobertos precisamente dez casos de doping. Na mesma época, muitos jogadores de futebol americano, atuantes em diversas temporadas, foram impedidos de jogar: 75 a $90 \%$ de todos os atletas usavam esteroides. É bom lembrar que essa é uma proporçâo epidêmica. (SANTOS, 2003, p. 116).

É importante assinalar que a utilizaçăo de substâncias dopantes representa um uso contrário à ética esportiva. Ao assistir um espetáculo esportivo, o público náo sabe se estará vendo um evento limpo ou sujo, uma competiçăo esportiva real ou um duelo entre indústrias farmacêuticas. Por isso, a trapaça deve ser punível com o banimento de atletas pelas federaçóes esportivas em caso de doping. Tal situaçáo ocorreu com o banimento da Rússia dos Jogos Olímpicos de Inverno de 2018 pelo Comitê Olímpico Internacional (COI), sob a acusaçáo de bancar uma teia de distribuiçâo de substâncias ilícitas para atletas (CHADE, 2017).

Zaffaroni e Pierangeli (2007, p. 230) definem o sistema penal, em sentido estrito, como um controle social punitivo institucionalizado, abrangendo o legislador, a polícia, os agentes penitenciários, os juízes, os promotores e o público. Enquanto que, em sentido amplo, existe o sistema penal paralelo (Direito Penal paralelo) que exerce poderes tal qual mente as instituiçóes que năo fazem parte do controle punitivo formal, a exemplo da Agência Mundial Antidoping (em inglês: World Anti-Doping Agency, WADA), da COI, das Federaçôes Esportivas Internacionais (em 
inglês: International Sports Federations, IFs), dos Comitês Olímpicos Nacionais (em inglês: National Olympic Committees, NOCs) e dos Comitês Organizadores dos Jogos Olímpicos (em inglês: Organising Committees of the Olympic Games,OCOGs).Já no Brasil, a Convençăo Internacional contra o Doping nos Esportes, celebrada em Paris em 19 de outubro de 2005, tem por objetivo promover a prevençăo e o combate ao doping nos esportes, com vistas a sua eliminaçăo (BRASIL, 2008).

Na opiniăo de González (2014, p. 14), as regras antidoping decorrentes da WADA têm alcance internacional; dito de outro modo, a intervençâo de um órgáo internacional de direitos humanos poderia esclarecer em que medida as obrigaçóes também se aplicam no domínio da atividade esportiva. Há três principais objetivos legítimos dessa luta contra o doping: proteger a saúde dos atletas, preservar a igualdade de oportunidades (concorrência) e manter a credibilidade da competiçáo esportiva.

A queda de heróis olímpicos lança uma apreensâo sobre os esportes, e as vítimas do doping desportivo nâo sâo apenas os rivais de quem foram subtraídas as medalhas olímpicas, mas todos os atletas "limpos" cujo desempenho é recebido com ceticismo (MCPHERSON, 2016, pp. 4-9). Para Silva (1999, pp. 3-10), o doping insere-se tanto no desporto em busca da capacidade física máxima quanto nas academias, visando a um corpo belo e forte em um curto espaço de tempo.

Já em relaçăo ao uso de anabolizantes fora de esportes profissionais, o estudo mostrou que meio milhăo de adolescentes nos Estados Unidos já os experimentou, provavelmente por causa da natureza altamente competitiva dos esportes no ensino médio e universitários (CASAVANT et al., 2007, p. 680). No Brasil, Iriart, Chaves e Orleans (2009, pp. 774-775) pontuam que o imediatismo na conquista do corpo desejado é o pináculo à prática da musculaçấo e ao consumo de EAAs por todas as classes sociais.

Diante dessa problemática, indaga-se: devemos aceitar o doping nos esportes? Se os estudantes tomam drogas para melhorar o desempenho cognitivo, por que năo consentir que os atletase desportistas façam o mesmo? A natureza náo é igual em dispensar a capacidade física e intelectual, entăo, deixe a ciência e o mercado livre dominarem o campo de jogo.

\subsection{FORMAS DE OBTENÇĀO DE EAAS}

Chama a atençâo o uso generalizado de EAAs no círculo de atletas e, também, por frequentadores de academias que querem ganho de força e hipertrofia muscular. De maneira geral, a utilizaçáo dessas drogas tem aumentado de maneira perigosa por esportistas amadores e recreativos, uma vez que as pessoas que as usam nâo estâo suficientemente informadas sobre todas as possíveis consequências, e as que o sáo desprezam os riscos.

As pessoas interessadas na aquisiçăo dessas drogas podem obtê-las de várias maneiras sub-reptícias. A primeira é pelo profissional do sistema de saúde, a exemplo da participaçăo de médicos que, embora năo haja indicaçăo, emitem uma prescriçăo de um esteroide em particular.

Lado outro, se um usuário em potencial năo obtém um receituário médico, tem a possibilidade de recorrer à aquisiçấo do documento em branco, com o qual, posteriormente 
preenchido falsamente, compra a medicaçâo necessária. Naturalmente, o sucesso desse método depende da habilidade dos falsificadores, mas também, em boa parte, da negligência do farmacêutico/atendente de farmácia.

Os EAAs produzidos pelos laboratórios farmacêuticos săo substâncias formuladas para serem administradas oral ou parenteticamente por via intradérmica, hipodérmica ou intramuscular. Sobre os riscos, Mcgrew (2015, p. 234) relata a própria existência dessas substâncias, mas afirma que săo seguras quando administradas adequadamente pelo médico para o tratamento de homens que sofrem de baixa testosterona, algumas formas de anemia, alguns cânceres de mama, osteoporose, endometriose e angioedema hereditário.

A maioria dos EAAs adquiridos no mercado clandestino têm maior probabilidade de serem alvo de falsificaçōes. Os usuários săo atraídos pelo menor preço e maior facilidade, já que as falsificaçôes de produtos farmacêuticos sâo uma ameaça invisível, năo somente pela natureza, mas também porque a indústria, agora, nâo só admite que a falsificaçāo é uma ameaça para seus negócios, mas, em alguns casos, trata publicamente de suas estratégias e tecnologias de combate (LYBECKER, 2007, pp. 512-513).

No mercado informal, Cecchetto, Moraes e Farias (2012, p. 371) relatam que os revendedores se comunicam pela internet ou na própria academia, ou por intermédio de amigos/conhecidos usuários dessas drogas para combinarem o tipo, a quantidade, o preço e a forma de entrega, e, por vezes, enviam-nas ao usuário pelo correio diretamente para o endereço residencial.

Comprar EAAs de qualquer vendedor pela internet é certamente a forma mais perigosa. A supervisăo mais rigorosa da produçăo pela Agência Nacional de Vigilância Sanitária(Anvisa)e a distribuiçâo de tais produtos proporcionada pelo rastreamento dos medicamentos pela Empresa Brasileira de Correios e Telégrafos (Correios) ${ }^{3}$ têm levado cada vez mais à compra de drogas falsificadas, em razăo da crescente demanda mundial por esses tipos de fármacos.

Ademais, como os normativos da Anvisa sobre o tema săo fragmentados, confusos e destoantes do arcabouço regulatório internacional, o estudo de Kyselovicova, Antala e Michalak (2008, p. 67) confirmou que a maioria das informaçóes sobre os efeitos anabolizantes é obtida pelos próprios atletas/desportistas, e é comum o uso de EAAs e drogas de estimulaçâo sem qualquer supervisâo médica.

Acontece, portanto, que esse melhor controle conduziu ao desenvolvimento de um grande mercado negro, de comercializaçăo e produçăo da substância, além dos adquiridos mediante receita médica. A estrutura de elaboraçăo e logística de EAAs se assemelha ao narcotráfico, embora em menor medida; de qualquer forma, alguns grupos do crime organizado geram grandes lucros.

No mercado paralelo, as preparaçōes importadas têm maior possibilidade de serem falsificadas, contendo apenas substâncias inertes ou nâo ativas. Muitas vezes sâo ilegalmente produzidas em condiçōes insalubres por fábricas clandestinas, o que é um grande perigo à integridade física e à saúde dos consumidores desavisados.

3 Os principais mecanismos a favor da autenticidade dos medicamentos foram a etiqueta de segurança e a rastreabilidade por código bidimensional (BRASIL, 2009). 


\section{A EXPERIÊNCIA JURÍDICA NORTE-AMERICANA SOBRE OS EAAS}

Ao longo das duas últimas décadas do século XX começou a crescer o número de naçôes a criminalizar o uso, a posse ou a venda de EAAs. Sua criminalizaçăo começou somente quando se teve conhecimento do seu abuso por desportistas e entusiastas do mundo fitness, especialmente por menores de idade, já que antes o consumo era restrito a atletas. Diante dessas informaçóes, os Estados Unidos foram um dos primeiros países a detectar a grande ameaça do aproveitamento dessas substâncias e decidiram criminalizar esse comportamento.

Em meados dos anos 1980, a mídia americana começou a noticiar o uso de EAAs no esporte e fora dele, particularmente entre os frequentadores de academias, o que levou a proposiçóes legislativas diante de uma necessidade de prever a responsabilidade criminal para tal conduta.

Entre 1988 e 1990 foram realizadas sessōes temáticas e audiências nas comissóes do Congresso, a fim de decidir se o normativo relativo às substâncias controladas colocaria os EAAs na lista de substâncias proibidas, a exemplo da cocaína e heroína. A maioria dos especialistas convidados, incluindo médicos especialistas e representantes de alguns órgáos federais, recomendaram a sua năo criminalizaçấo (LEITE, 2013, p. 144).

A Associaçăo Médica Americana (American Medical Association - AMA) apontou que o abuso de EAAs náo leva à dependência física ou psíquica, que é uma das principais condiçôes para fazer uma substância vir a ser controlada. Entretanto, após parecer técnico do órgáo de controles de medicamentos e alimentos, o Food and Drug Administration (FDA),este instruiu o Congresso americano à aprovaçấo de regramento que criminalizou a distribuiçâo e posse de certos precursores de esteroides, anteriormente a cargo dos Estados,que determinavam a existência de uma substância ameaçadora à saúde do público em geral (WILAIRAT, 2005, p. 403).

Ignorando um ponto de vista técnico, o Congresso Americano, em 1990, promulgou a lei relativa ao controle dos EAAs colocando-os na lista das substâncias controladas. Nesse aspecto, destaca Santos (2003, p. 5):

Em $1^{\circ}$ de março de 1991, nos Estados Unidos, a Lei de Controle Federal de Anabólicos (Federal Anabolic Control Act) tornava-se fato. Ela inclui os esteróides anabólicos sobre o Programa III da Lei de Controle de Substância (Controlled Substance Act) tornando-os uma substância ilegal sem prescriçăo.

No interregno das discussōes, em 1989 e 1990, cerca de 22 estados americanos já haviam criminalizado os EAAs nas suas próprias legislaçōes. Durante esse período (até 1991) houve um reforço do controle sobre o uso. De modo geral, essas leis prescreviam penas de diferentes graus, dependendo do tipo da droga.

Houve críticas relativas à sua suposta inconstitucionalidade, assim como a inadequaçấo para alcançar o efeito desejado na luta contra o uso de EAAs. A lei federal promulgada em 1990 foi alterada em 2004 por outra ainda mais rigorosa, expandindo a lista de substâncias proibidas, a fim de colmatar as lacunas legislativas indicadas na lei penal anterior, o que permitiu, temporariamente, que muitos atletas pudessem usar preparaçóes hormonais para fins recreativos. 


\subsection{TRATAMENTO JURÍDICO-PENAL DOS EAAS NO BRASIL}

O Estado detém certas normas que se destinam a combater essa ameaça pela política criminal garantista, cuja sociedade vislumbra na pena um mecanismo de prevençăo positiva. Ressalte-se a atipicidade penal do doping esportivo no Brasil, visto que o Poder Executivo enxerga que "As regras antidoping năo săo concebidas para estarem sujeitas a, ou limitadas por, requisitos e padrôes legais aplicáveis aos procedimentos criminais ou questōes trabalhistas." (BRASIL, 2008).

Com efeito, o Projeto de Lei do Senado n. 124/2005 (BRASIL, 2005), de autoria do Senador Papal é o Paes (PMDB/AP), teve sua tramitaçăo encerrada. O Projeto tencionava criminalizar quem vende ou dispensa medicamentos do grupo terapêutico dos esteroides ou peptídeos anabolizantes, para uso humano ou veterinário, em descumprimento ao disposto nessa lei, e no seu regulamento, com pena de reclusăo de três a 15 anos e pagamento de multa (equivalente à do tráfico ilícito de substância entorpecente).Seu arquivamento, em parte,decorreu da inconstitucionalidade pela Corte Especial do Superior Tribunal de Justiça por sançăo desproporcional para o tipo penal que trata da venda de produto destinado a fins terapêuticos ou medicinais de procedência incerta(BRASIL, 2012). ${ }^{4}$

Fora dos esportes, os usuários que se dopam por vontade livre e conscientemente também năo respondem em face do princípio da reserva legal ou da anterioridade, pois "a expressăo usar, que significa 'fazer uso de, servir-se de ou empregar' năo foi abrangida no tipo penal e, nesse sentido, năo pode o juiz alargar as hipóteses estabelecidas pelo legislador." (SILVA, 1999, p. 79).Sob essa perspectiva,Ferro(2014, p. 48) pontua que a venda ilegal de EAAs no Brasil é uma atividade ilícita, mas năo configura tráfico de entorpecentes, portanto os EAAs têm sua venda restrita às drogarias mediante a apresentaçăo de prescriçăo médica.

Quanto às outras pessoas que produzem e/ou comercializam EAAs, elas podem ser responsabilizadas por determinadas infraçóes previstas no Código Penal (BRASIL, 1940) ou em legislaçăo extravagante (BRASIL, 2006); nesse sentido, a construçâo jurisprudencial e a doutrinária proporcionam uma gama interpretativa diante dos postulados da ofensividade, da intervençăo mínima, da fragmentariedade, da insignificância, da anterioridade da lei e da reserva legal.

Relevante salientar que os EAAs têm sua dispensaçâo ou a venda restrita à "Receita de Controle Especial" em duas vias, uma a ser retida na drogaria e outra disponibilizada ao paciente, nos termos do artigo $1^{\circ}$, da Lei n. 9.965/2000 (BRASIL, 2000a) e pormenorizada na Resoluçáo da Diretoria Colegiada (RDC) n. 36, de 2011(AGÊNCIA NACIONAL DE VIGILÂNCIA SANITÁRIA, 2011).

Considerando a soluçăo legislativa, o primeiro crime possível para explicar o abuso de EAAs encontra-se nas plúrimas açôes do artigo 273 , parágrafo $1^{\circ} \mathrm{B}$, do Código Penal (BRASIL, 1940, 2000), que prevê pena de 10 a 15 anos de reclusăo àqueles que violam a norma proibitiva de

4 "Art. 273-Falsificar, corromper, adulterar ou alterar produto destinado a fins terapêuticos ou medicinais: [...] $\S 1^{\circ}$-B - Está sujeito às penas deste artigo quem pratica as açôes previstas no $\S 1^{\circ}$ em relaçâo a produtos em qualquer das seguintes condiçōes: [...] V - de procedência ignnorada;" (BRASIL, 1940). 
Falsificar, corromper, adulterar ou alterar produtos destinados a fins terapêuticos ou medicinais [...] Nas mesmas penas incorre quem importa, vende, expōe à venda, tem em depósito para vender ou, de qualquer forma, distribui ou entrega a consumo o produto falsificado, corrompido, adulterado ou alterado. (BRASIL, 1940).

Essas várias condutas foram sancionadas por refletirem e realizarem um sentido de injusto penal próprio, objetivado pelo legislador, desde que os anabolizantes estejam/sejam: sem registro, quando exigível, no órgăo de vigilância sanitária competente; em desacordo com a fórmula constante do registro previsto no inciso anterior; sem as características de identidade e qualidade admitidas para a sua comercializaçáo; com reduçăo de seu valor terapêutico ou de sua atividade; de procedência ignorada; ou adquiridos de estabelecimento sem licença da autoridade sanitária competente.

A intençấo dessa figura típica é o resguardo do bem jurídico saúde pública de apenar nâo somente a produçấo fraudulenta de medicamentos e produtos congêneres, mas também os desrespeitos aos controles de vigilância sanitária executados pela Anvisa (DELGADO, 2015). Nessa perspectiva, a sétima turma do Tribunal Federal da 4ª Regiâo (BRASIL, 2010b) posicionou-se que a importaçâo clandestina de fármacos em grande quantidade visando ao comércio incide o art. $273, \S 1^{\circ}$ - $B$, inc. I do Código Penal (BRASIL, 1940), cujo trecho do acordâo transcreve-se:

Na importaçăo de pequenas quantidades de medicamentos, sem especial potencial lesivo à saúde pública, incide a norma geral de puniçăo à importaçáo de produto proibido, o contrabando, do art. 334 do CP. 2. Na espécie, tratando-se de grande quantidade de medicamentos, deve incidir a regra do artigo 273 do Código Penal, cuja alta pena cominada - de dez a quinze anos de reclusáo e multa - decorre, justamente, da especial proteçăo à saúde pública como ente coletivo, atingida pelo risco jure et de jure da falsificaçáo ou venda de remédios sem controle em grande quantidade - com alto gravame social.

O fato é que săo integralmente turvos os aspectos penais relacionados aos EAAs, e, por essa razâo, a jurisprudência pátria năo é uníssona. Em alguns casos, entendese pela absolviçăo da conduta insculpida no artigo 273, parágrafos $1^{\circ}$ e $1^{\circ}$-B, inciso I, do Código Penal pelos parâmetros sancionatórios do artigo 33 da Lei n. 11.343, de 23 de agosto de 2006, pois os EAAs constam da Lista "C5" (Lista de Substâncias Anabolizantes) preconizada pela Portaria n. 344, de 12 de maio de 1998, da antiga Secretaria de Vigilância Nacional do Ministério da Saúde, atualizada na Resoluçāo da Diretoria Colegiada - RDC n. 36, de 2011 (AGÊNCIA NACIONAL DE VIGILÂNCIA SANITÁRIA, 2011), e devem ser considerados "droga", nos termos do artigo 66 do mesmo regramento emface ao princípio da especialidade da norma penal.

Nesse ponto, a segunda turma do Tribunal Regional Federal da $3^{\text {a }}$ Regiâo parece ter uma concepçáo diferenciada da questâo por entender que a sançáo cominada para o artigo 273, parágrafos $1^{\circ}$ e $1^{\circ}-\mathrm{B}$, inciso I, do Código Penal5 é desproporcional, náo adequada e desnecessária ao fim a que se presta a norma repressiva, sendo

5 "Art.273-Falsificar, corromper, adulterar ou alterar produto destinado a fins terapêuticos ou medicinais: Pena - reclusăo, de 10 (dez) a 15 (quinze) anos, e multa." (BRASIL, 1940). 
medida pelo tempo de reclusăo fixado ao condenado em relaçăo do artigo 33 da Lei n. 11.343, de 2006.6 Esse entendimento foi sopesado pela interpretaçáo sistemática da importaçăo de EAAs e demais produtos utilizados no tratamento de disfunçâo erétil sem registro na Anvisa aliada ao contexto histórico-legislativo no qual esta norma foi elaborada, assim redigida:

A materialidade foi plenamente comprovada pelo Auto de Prisáo em Flagrante (fls. 02/04) e pelo Auto de Apresentaçăo e Apreensăo (fls. 14/15), o qual elencou as substâncias encontradas no compartimento do tanque do veículo usado pelo réu. 0 Laudo de Exame de Produto Farmacêutico (fls. 118/126) atestou que os produtos apreendidos năo sâo registrados na ANVISA e parte deles é de origem ignorada, sendo sua importaçáo proibida. [...] A alegaçáo de destinaçáo do material para uso próprio năo é crível, dada a quantidade e a diversidade de produtos anabolizantes e medicamentos destinados ao tratamento de disfunçăo erétil. A configuraçáo do tipo penal do art. $273, \S 1^{\circ}-\mathrm{B}$, do $\mathrm{CP}$, independe da demonstraçăo de risco efetivo dos medicamentos ou que tenham sido estes adulterados, corrompidos ou falsificados. A criaçăo desta figura típica pela Lei 9.677/98 veio justamente para reprimir penalmente a conduta de perigo abstrato de importar produto terapêutico ou medicinal em desconformidade com o controle da vigilância sanitária. [...] Face aos princípios da proporcionalidade e da razoabilidade, é nítido o rigor excessivo empregado pelo legislador na fixaçăo da pena mínima aplicável aos delitos do art. $273, \S 1^{\circ}$ e $\S 1^{\circ}-\mathrm{B}$, do CP. A interpretaçáo sistemática da legislaçáo penal conduz à adoçăo da pena mínima aplicável ao crime de tráfico de drogas (art. 33, da Lei 11.343/06) como parâmetro na dosimetria da pena a ser cominada para o delito em tela. Manutençăo da pena em 05 (cinco) anos e 10 (dez) meses de reclusăo, para cumprimento inicial em regime fechado, e 580 (quinhentos e oitenta) dias-multa. (BRASIL, 2010d).

Diante da sofisticaçăo dos casos tem-se aceitado a tese da desclassificaçăo do artigo 33 da Lei n. 11.343, de 2006, para a figura do contrabando quando se trata de internaçăo irregular de pequena quantidade de anabolizante hormonal, conforme disposto no artigo 334 do Codex Repressivo. Nessa linha, a Sétima Turma do Tribunal Federal da $3^{a}$ Regiăo (BRASIL, 2010c) proferiu nos autos da ACR n. 500526161.2014.404.7002, em 09 de setembro de 2015, relatada pela Desembargadora Federal Cláudia Cristina Cristofani, a seguinte ementa: "[...] Sendo bastante diminuta a quantidade de anabolizantes introduzidos no país, é possível a reclassificaçăo da conduta para aquela constante do art. 334 do CP."

Em outra situaçăo, a depender das declaraçóes do agente, da quantidade (moderada) e da natureza (consumo próprio), pode-se aplicar a insignificância da conduta, afastando, assim, o preceito incriminador de contrabando (artigo 334, do Código Penal). Nessa corrente de pensamento, a sétima turma do Tribunal Federal da $4^{\text {a }}$ Regiâo (BRASIL, 2010c) acordou nos seguintes termos:

Na importaçấo de pequena quantidade de medicamento de uso controlado incide a norma geral de puniçâo à importaçăo de produto proibido (contrabando), prevista

6 "Art. 33. Importar, exportar, remeter, preparar, produzir, fabricar, adquirir, vender, expor à venda, oferecer, ter em depósito, transportar, trazer consigo, guardar, prescrever, ministrar, entregar a consumo ou fornecer drogas, ainda que gratuitamente, sem autorizaçáo ou em desacordo com determinaçáo legal ou regulamentar: Pena - reclusáo de 5 (cinco) a 15 (quinze) anos e pagamento de 500 (quinhentos) a 1.500 (mil e quinhentos) dias-multa." (BRASIL, 2006). 
no art. 334 do Código Penal, admitindo-se a aplicaçăo do princípio da insignificância quando comprovado que o medicamento se destinava ao uso próprio do agente, em face da ausência de potencial lesivo à saúde pública.

Divergente julgado da terceira turma do Tribunal Regional Federal da $5^{a}$ Regiăo (BRASIL, 2014a) entende pela inaplicabilidade da bagatela da prática delituosa, pois se trata de crimes praticados contra a saúde pública, porque a ofensa ao referido bem jurídico năo pode ser mensurada pelo valor da lesâo ou pela reduzida porçấo de substância proibida comercializada. Nesse sentido, o tipo penal busca proteger a salubridade das circunstâncias de saúde da populaçăo.

Busato (2012, p. 149), ao abordar a matéria, procura firmar um desenho aproximado de identificaçáo com o direito alemăo que o tema é tratado năo somente a partir do interesse na saúde, mas também se utiliza da "técnica dos crimes de perigo para alcançar a mera posse dos produtos potencialmente danosos." Sinaliza-se, entâo, o julgado da oitava turma do Tribunal Federal da 4ª Regiăo (BRASIL, 2011) quanto à importaçáo de medicamento sem fim mercantil:

A importaçăo de pequena quantidade de medicamento para uso pessoal, por năo caracterizar especial potencial lesivo à saúde pública, enquadra-se no delito previsto pelo art. 334, caput, primeira figura, do Código Penal, e năo no do art. 273 , $\S \S 1^{\circ}$ e $1^{\circ}$-B, do Estatuto Repressor, que se destina à capitulaçăo de importaçăo de fármacos para venda e comercializaçăo.

Há, ainda, a possibilidade da desclassificaçáo do delito para o previsto no artigo 28 da Lei n. 11.343, de 2006(aquisiçăo de drogas para uso próprio), e, assim, angariar a declaraçâo da extinçấo da punibilidade do usuário, devendo os fatos ser devidamente apurados. Nesse campo de discussāo, Busato (2012, p. 150) explicita hipótese de autolesáo, pois o dano à saúde aflige a si próprio, estando impune "porque existe uma esfera de autonomia dos indivíduos claramente abrangente do próprio corpo, sobre a qual ao Estado náo cabe interferir." A título exemplificativo segue o entendimento assaz liberal da sétima turma do Tribunal Federal da 4ª Regiăo (BRASIL, 2014b) concernente a essa matéria:

[...] Em sendo diminuta a quantidade de medicamentos introduzidos no país, é possível a reclassificaçáo da conduta para aquela constante do art. 334 do CP. Resultando claro que o anabolizante TESTOGAR foi internalizado em solo pátrio para exclusiva utilizaçăo pessoal, năo há como verificar lesăo à saúde pública ou à coletividade, de modo, que no caso concreto, mostra-se cabível o reconhecimento da atipicidade da conduta pela aplicaçáo do princípio da insignificância. [...] No caso em tela, em que foi apreendida pouca quantidade e náo há dúvidas de que é destinada ao uso pessoal do acusado, a conduta de importá-la sem autorizaçăo da ANVISA náo causa lesividade à saúde pública, devendo também ser considerada insignificante penalmente.

Portanto, no caso de possuir pequena monta de substância dopante, ressalvado o traficante/comerciante, o combate ao uso de EAAs sob o pálio da tutela da saúde individual ou coletiva fica superado pela autorresponsabilidade, dispensando, entăo, a preocupaçăo do legislador penal. Por sua vez, parcela da sociedade civil tem se mobilizado com a criaçăo de modelos interdisciplinares mitigadores das consequências do uso de EAAs, a exemplo do Programa Apolo (\#Bomba Tô Fora) da Universidade 
Federal de Sáo Paulo (Unifesp),que busca conscientizar pela educaçăo e reabilitar seus usuários (MACEDO et al., 2017, p. 82-84).

Skårberg, Nyberg e Engström (2010, p. 218) indicam uma associaçăo entre o uso de EAAs e a criminalidade, especialmente crimes de violência, ao sustentarem que o uso de esteroides é um fator significativo para o comportamento criminal. 0 estudo baseou-se em entrevistas e dados de criminalidade envolvendo 32 usuários que buscaram tratamento da dependência em uma clínica psiquiátrica na Suécia com a verificaçâo do aumento do nível de atividade criminal em 69\% dos indivíduos após terem começado a usar tais drogas.

De fato, existe uma relaçâo desses acontecimentos com a atuaçấo da criminalidade organizada por meio de redes ilícitas de delinquentes que se beneficiam duplamente. Ocorre com o fornecimento dos EAAsutilizados no doping de atletas e desportistas, aliado ao dinheiro em grande espécie recolhido nos mercados de apostas que se envolvem em fraudes e atos de corrupçâo decorrentes da contrafaçăo de resultados (PEREIRA, 2015, p. 125).

Roxin, Greco e Leite(2011, p. 43), ao analisarem as novas tendências, prelecionam que o Direito nâo deve castigar penalmente as pessoas que recorrem a drogas estimulantes, independentemente de serem prejudiciais à saúde, pois "[...] năo resta nenhum fundamento político-criminal racional para proteger apenas a saúde do atleta, contra a sua vontade, de prejuízos causados por substâncias dopantes, enquanto todas as outras permanecem desprotegidas a esse respeito."

Cabe ressaltar, ainda, que o médico responde quando há prescriçāo ou ministraçăo culposa de EAAs, sem a necessidade de tratamento ou de forma inadequada ou descuidada, bem como a prescriçăo intencional, isto é, quando o profissional tem ciência de que está agindo de uma forma que diverge claramente das regras da profissăo, situaçâo essa inusitada em razâo dos princípios morais e éticos profissionais (BRASIL, 1940, 2013). ${ }^{7},{ }^{8}$ Além disso, o tipo penal de fornecer medicamento em dissonância com o receituário médico à obtençâo de EAAs é um crime próprio, visto que sua comercializaçâo é controlada (BRASIL, 1940). ${ }^{9}$

\section{CONSIDERAÇÕES FINAIS}

Os EAAs afetam a aparência, a habilidade (força, potência, velocidade muscular) e o comportamento que se ligam ao respeito, poder e recompensas, às vezes, financeiras. Por outro lado, o conhecimento dos riscos/efeitos colaterais - como elemento dissuasivo do seu consumo - tem baixa influência diante da tolerância da sociedade.

$7 \quad \mathrm{O}$ artigo $4^{\circ}$, incisos II e X, descreve que é ato privativo do médico a prescriçăo dos cuidados médicos pré e pós-operatórios e a determinaçăo do prognóstico relativo ao diagnóstico nosológico que, antes dessa Lei, os odontólogos poderiam diagnosticar doenças e prescrever o tratamento correlato (BRASIL, 2013).

8 “Art. 38. Prescrever ou ministrar, culposamente, drogas, sem que delas necessite o paciente, ou fazê-lo em doses excessivas ou em desacordo com determinaçâo legal ou regulamentar: Pena - detençâo, de 6 (seis) meses a 2 (dois) anos, e pagamento de 50 (cinquenta) a 200 (duzentos) dias-multa." (BRASIL, 1940).

9 "Art. 280 - Fornecer substância medicinal em desacordo com receita médica: Pena - detençâo, de um a três anos, ou multa. Parágrafo único - Se o crime é culposo: Pena - detençáo, de dois meses a um ano." (BRASIL, 1940). 
Ou seja, a prevalência do uso de EAAs para fins náo terapêuticos indica, até certo ponto, que os normativos restritivos estăo aquém da proteçâo da saúde individual/ pública, todavia,dentro do sistema penal o próprio direito penal ocuparia um lugar limitado.

Assim, a constataçăo do uso de EAAs movido pelo imperativo estético, notadamente entre a populaçăo masculina jovem, leva à conclusăo de que os esforços contra o abuso de esteroides afastam a intervençăo da instância penal, transferindo a puniçăo para o campo esportivo e exigindo investimentos em educaçâo sobre as suas consequências.

Se, por um lado, tanto atletas profissionais quanto amadores devem buscar uma vida saudável e em equilíbrio, segundo a antiga citaçâo latina da mens sana in corpore sano, por outro lado,os efeitos do uso em altas doses de esteroides sâo, em grande parte, desconhecidos em longo prazo.

No mais, conclui-se que as campanhas de informaçăo sobre os riscos da administraçăo de EAAs para jovens sâo necessárias, visto que essa faixa etária está sujeita às pressóes de grupos em prol de uma imagem projetada para um corpo perfeito. Quanto aos elementos do delito de comercializaçăo do produto que gerem riscos à saúde pública, o volume do produto transacionado e a possibilidade de reiteraçáo criminosa sâo peculiaridades que, se inobservadas, podem descaracterizar o instituto. 


\section{REFERÊNCIAS BIBLIOGRÁFICAS}

ABRAHIN, Odilon Salim Costa; SOUSA, Evitom Corrêa de. Esteroides anabolizantes androgênicos e seus efeitos colaterais: uma revisăo crítico-científica. Revista da Educaçăo Física, UEM, v. 24, n. 4, pp. 669-679, 4. trim. 2013. Disponível em: <http://www.scielo.br/ pdf/refuem/v24n4/14.pdf> Acesso em: 06 abr. 2018.

AGÊNCIA NACIONAL DE VIGILÂNCIA SANITÁRIA. Resoluçăo da Diretoria Colegiada - RDC n 36, de 3 de agosto de 2011. Dispóe sobre a atualizaçăo do Anexo I, Listas de Substâncias Entorpecentes, Psicotrópicas, Precursoras e Outras sob Controle Especial, da Portaria SVS/MS nº 344, de 12 de maio de 1998 e dá outras providências. Diário Oficial da Uniăo nº 150 - Seçáo 1, 05 ago. 2011. Disponível em: <http://www.anvisa.gov. br/hotsite/talidomida/legis/RDC_36_2011.pdf> Acesso em: 06 jan. 2018.

BRASIL. Decreto-Lei n. 2.848, de 07 de dezembro de 1940. Código Penal.Diário Oficial da Uniăo,Brasília, DF, 07 dez. 1940. Disponível em: <http://www.planalto.gov.br/ccivil_03/ decreto-lei/Del2848compilado.htm> Acesso em: 13 jan. 2018.

BRASIL. Decreto n. 6.653, de 18 de novembro de 2008. Promulga a Convençáo Internacional contra o Doping nos Esportes, celebrada em Paris, em 19 de outubro de 2005. Diário Oficial da Uniăo,Brasília, DF, 18 dez. 2008. Disponível em: <http://www. planalto.gov.br/ccivil_03/_ato2007-2010/2008/decreto/d6653.htm> Acesso em: 07 jan. 2018.

BRASIL. Lei n. 11.343, de 23 de agosto de 2006. Institui o Sistema Nacional de Políticas Públicas sobre Drogas - Sisnad; prescreve medidas para prevençăo do uso indevido, atençâo e reinserçâo social de usuários e dependentes de drogas; estabelece normas para repressâo à produçáo nâo autorizada e ao tráfico ilícito de drogas; define crimes e dá outras providências. Diário Oficial da Uniăo,Brasília, DF, 23 ago. 2006. Disponível em: <http://www.planalto.gov.br/ccivil_03/_ato2004-2006/2006/lei/111343.htm> Acesso em: 13 jan. 2018.

BRASIL. Lei n. 11.903, de 14 de janeiro de 2009. Dispóe sobre o rastreamento da produçấo e do consumo de medicamentos por meio de tecnologia de captura, armazenamento e transmissăo eletrônica de dados. Diário Oficial da Uniăo,Brasília, DF, 14 jan. 2009. Disponível em: <http://www.planalto.gov.br/ccivil_03/_Ato2007-2010/2009/Lei/ L11903.htm> Acesso em: 05 jan. 2018.

BRASIL. Lei n. 12.842, de 10 de julho de 2013.Dispōe sobre o exercício da Medicina. Diário Oficial da Uniăo,Brasília, DF, 10 jul. 2003. Disponível em: <http://www.planalto. gov.br/ccivil_03/_Ato 2011-2014/2013/Lei/L12842.htm> Acesso em: 13 jan. 2018.

BRASIL. Lei n. 9.677, de 2 de julho de 2000.Altera dispositivos do Capítulo III do Título VIII do Código Penal, incluindo na classificaçăo dos delitos considerados hediondos crimes contra a saúde pública, e dá outras providências. Diário Oficial da Uniăo,Brasília, DF, 02 jul. 2000a. Disponível em: <http://www.planalto.gov.br/CCIVIL_03/leis/L9677. htm> Acesso em: 09 jan. 2018. 
BRASIL. Lei n. 9.965, de 27 de abril de 2000. Restringe a venda de esteroides ou peptídeos anabolizantes e dá outras providências. Diário Oficial da Uniăo,Brasília, DF, 27 abr. 2000b. Disponível em: 〈http://www.planalto.gov.br/ccivil_03/Leis/L9965.htm〉 Acesso em: 09 jan. 2018.

BRASIL. Senado Federal. Projeto de Lei do Senado n. 124, de 2005. Altera o art. $2^{\circ}$ da Lei $n^{\circ}$ 9.965, de 27 de abril de 2000, que restringe a venda de esteróides ou peptídeos anabolizantes e dá outras providências, para tipificar a venda desses produtos como crime punível com penas equivalentes às do tráfico ilícito de substância entorpecente. Comissâo de Assuntos Sociais, Senado Federal, 2005. Disponível em: <https://is.gd/ pYPNTb> Acesso em: 13 abr. 2018.

BRASIL. Superior Tribunal de Justiça. Arguiçăo de Inconstitucionalidade no Habeas Corpus n 239363 - PR (2012/0076490-1). Relator para acórdâo: Ministro Sebastiâo Reis Júnior. Órgāo Julgador: Sexta Turma. Diário de Justiça eletrônico, 18 dez. 2012.

Conflito de competência n 2013/0197794-2. Relator para acórdāo: Ministro Newton Trisotto. Órgâo Julgador: Terceira Turma. Diário de Justiça eletrônico, 01 set. 2015a.

BRASIL. Supremo Tribunal Federal. Habeas Corpus (HC) n 76.203/SP. Relator para acórdāo: Ministro Nelson Jobim. Órgāo Julgador: Segunda Turma. Diário de Justiça, 17 nov. 2000c.

Recurso Ordinário em Habeas Corpus n 2015/0080030-7. Relator para acórdáo: Ministro Leopoldo de Arruda Raposo. Órgăo Julgador: Quinta Turma. Diário de Justiça eletrônico, 05 dez. 2015b.

Habeas Corpus (HC) n²009/0208334-9. Relator para acórdāo: Ministra Laurita Vaz. Órgăo Julgador: Quinta Turma. Diário de Justiça eletrônico, 14 jun. 2010a.

BRASIL. Tribunal Federal da $4^{a}$ Regiăo. Apelaçăo Criminal (ACR) $n^{0}$ 501378178.2012.404.7002/PR. Relatora Desembargadora Federal Cláudia Cristina Cristofani. Órgâo Julgador: Sétima Turma. Julgamento em 21 out. 2014b.

Recurso Criminal em Sentido Estrito (RSE) n 0000665-32.2008.404.7002/PR. Relator: Desembargador FederalPaulo Afonso Brum Vaz. Órgăo Julgador: Oitava Turma. Julgamento em 28 set. 2011.

Recurso Criminal em Sentido Estrito (RSE) $n^{\circ}$ 0000334-79.2010.404.7002/ PR. Relator: Desembargador Federal Néfi Cordeiro. Órgăo Julgador: Sétima Turma. Julgamento em 29 out. 2010b.

Recurso Criminal em Sentido Estrito (RSE)nº 0001302-25.2009.404.7106/PR. Relator Desembargador Federal Márcio Antônio Rocha. Órgăo Julgador: Segunda Turma. Julgamento em 18 nov. 2010c.

BRASIL. Tribunal Federal da $5^{a}$ Regiâo. Habeas Corpus (HC) n 5625/RN. 2014. Relator: Desembargador Federal Geraldo Apoliano. Órgăo Julgador: Terceira Turma. Julgamento em 30 out. 2014 a.

BRASIL. Tribunal Regional Federal da $3^{a}$ Regiâo. Apelaçăo Criminal (ACR) nº 0002736 35.2010.4.03.6106/SP. Relator: Desembargador Federal Luis Paulo Cotrim Guimarâes. Órgáo Julgador: Segunda Turma. Julgamento em 15 fev. 2010d. 
BUSATO, Paulo César. Doping, Delimitaçăo do Interesse Jurídico-Penal e Fórmula Omissiva. Revista Brasileira de Ciências Criminais, Săo Paulo: Revista dos Tribunais, a. 20, v. 95, pp. 148-161, mar./abr.2012.

CAMILO, Juliana Aparecida de Oliveira; FURTADO, Rafael Nogueira. Doping e a lógica da escolha. AtheneaDigital, v. 17, n. 1, pp. 23-41, mar. 2017. Disponível em: <http://dx.doi. org/10.5565/rev/athenea.1670>. Acesso em: 05 fev. 2018.

CASAVANT, Marcel J. et al.Consequences of Use of Anabolic Androgenic Steroids. Pediatric Clinics, v. 54, i. 4, pp. 677-690, Aug. 2007. Disponível em: <http://dx.doi.org/10.1016/j.pcl.2007.04.001>. Acesso em: 04 fev. 2018.

CECCHETTO, Fátima; MORAES, Danielle Ribeiro de; FARIAS, Patrícia Silveira de. Distintos enfoques sobre esteroides anabolizantes: riscos à saúde e hipermasculinidade. Interface- Comunicaçăo, Saúde, Educaçăo, v. 16, n. 41, pp. 369-82, abr./jun. 2012. Disponível em: 〈https://www.scielosp.org/pdf/icse/v16n41/aop0612.pdf〉. Acesso em: 05 abr. 2018.

CHADE, Jamil. Por 'doping de estado', COI bane Rússia dos Jogos de Inverno de 2018. 0 Estado de Sáo Paulo, Genebra, 05 dez. 2017. Disponível em: 〈https://is.gd/p6HRjX〉. Acesso em: 26 abr. 2018.

DELGADO, Joedson de Souza. Regulaçăo sanitária: atribuiçăo da Agência Nacional de Vigilância Sanitária em prol da saúde pública.Revista Direito e Desenvolvimento, Joâo Pessoa, v. 6, n. 12, pp. 107-119, 2015b. Disponível em: 〈https://is.gd/eMiAOP〉. Acesso em: 09 fev. 2018.

ELLIOT Diane L.; GOLDBERG Linn, Intervention and prevention of steroid use in adolescents. American Journal of Sports Medicine: SAGE Journals, v. 24, i. 6, pp. S46-S47, 1996. Supplement. Disponível em: 〈https://www.ncbi.nlm.nih.gov/pubmed/8947428>. Acesso em: 04 mar. 2018.

FERRO, Najara Flauzino. Legislaçăo antidoping: uma análise crítica do seu caráter punitivo. 2014. 61 p. Monografia (Graduação)-Faculdade de Ciências Jurídicas e Sociais, Centro Universitário de Brasília, Brasília, DF, 2014. Disponível em: <http://repositorio. uniceub.br/bitstream/235/5521/1/20810861.pdf>. Acesso em: 13 mar. 2018.

GONZÁLEZ, Carmen Pérez. International Sports Law and the Fight Against Doping: An Analysis from an International Human Rights Law Perspective (September 4, 2014). European Society of International Law, 10th Anniversary Conference, Vienna, 4-6 Sept. 2014.Conference Paper $n^{\circ}$ 5/2014. Disponível em: <http://dx.doi.org/10.2139/ ssrn.2546141>. Acesso em: 29 abr. 2018.

GREYDANUS, DonaldE.; PATEL, DilipR. Sports doping Sports doping in the adolescent athlete the hope, hype, and hyperbole.Pediatric Clinics of North America, v. 49, p. 829855, Aug. 2002. Disponível em: 〈https://www.ncbi.nlm.nih.gov/pubmed/12296535〉. Acesso em: 04 mar. 2018.

IP, Eric et al. Psychological and Physical Impact of Anabolic-Androgenic Steroid Dependence. Pharmacotherapy, v. 32, i. 10, pp. 910-919, 2012. Disponível em: <http:// dx.doi.org/10.1002/j.1875-9114.2012.01123>. Acesso em: 30 mar. 2018.

IRIART, Jorge Alberto Bernstein; CHAVES, José Carlos; ORLEANS, Roberto Ghignone de. Culto ao corpo e uso de anabolizantes entre praticantes de musculaçăo. Cadernos de 
Saúde Pública,Rio de Janeiro,v.25, n.4, 2009. Disponível em:<http://dx.doi.org/10.1590/ S0102-311X2009000400008>. Acesso em: 04 abr. 2018.

LEITE, Alaor. O que náo se pode definir, tampouco se deve criminalizar: novas reflexóes sobre a criminalizaçâo do doping. Revista Brasileira de Ciências Criminais,Sâo Paulo: Revista dos Tribunais a. 21, v. 105, pp. 122-155, nov./dez.2013.

LYBECKER, Kristina M. Rx Roulette: combatting counterfeit pharmaceuticals in developing nations. Managerial \& Decision Economics, v. 28, i. 4-5, pp. 509-520, jun. 2007. Disponível em: 〈https://is.gd/Jvysrt>. Acesso em: 03 mai. 2018.

KANAYAMA, Gen etal.Anabolic-Androgenic Steroid Dependence: An Emerging Disorder. Addiction, vol. 104, issue12, p. 1966-1978, Dec. 2009. Disponível em:<http://dx.doi.org/1 0.1111/j.1360-0443.2009.02734.x>. Acesso em: 04 abr. 2018.

KYSELOVICOVA, Olga; ANTALA, Branislav;MICHALAK, Karol. The use of Anabolic Steroids in men's recreational Fitness Training.Fitness \& Performance Journal, v. 7, i. 2, pp. 65-68, 2008.Disponível em:〈http://dx.doi.org/10.3900/fpj.7.2.65.e〉 Acesso em:04 mar. 2018.

MACEDO, Clayton Luiz Dornelleset al. Uso de esteroides anabolizantes e similares: um problema social e de saúde pública. E-legis, Brasília, DF, n.esp., Pesquisas e Políticas sobre Esporte, dez. 2017. Disponível em: 〈https://is.gd/CR1j01> Acesso em: 04 abr. 2018.

MACHADO, Anderson Geraldo; RIBEIRO, Paulo César Pinho. Anabolizantes e seus riscos. Adolescência \& Saúde, v. 1, n. 4, out./dez. 2004. Disponível em: 〈https://is.gd/wc2JJj〉. Acesso em: 04 abr. 2018.

MCGREW, Ryan J. Raising the bar: why the anabolic steroid control acts should be repealed and replaced. Houston Journal of Health Law \& Policy, v. 15, i. 1, p'p. 233-252, 2015. Disponível em: 〈https://is.gd/sOQYiw> Acesso em:18 mar. 2018.

MCPHERSON,StephanieSammartino.Dopinginsports:winningatanycost? Minneapolis, EUA: Twenty-First Century Books, 2016.

MORAES, Thiago Perez Bernardes de. Anabolizantes nas buscas da web. Um estudo sobre o interesse sazonal por esteroides anabolizantes no Brasil. Revista jurídica luso brasileira, a. 1, n. 1, pp. 1979-2007, 2015. Disponível em: 〈https://is.gd/u0jGID〉. Acesso em: 17 mar. 2018.

NEUMARK-SZTAINER, Dianneet al. Sociodemographic and Personal Characteristics of Adolescents Engaged in Weight Loss and Weight/Muscle Gain Behaviors: Who Is Doing What? Preventive Medicine, v. 28, i. 1, pp. 40-50, Jan. 1999. Disponível em: <https://doi. org/10.1006/pmed.1998.0373>. Acesso em: 04 mar. 2018.

PALERMO-NETO, Joâo. Anabolizantes.In: SPINOSA, Helenice de Souza; GÓRNIAK, Silvana Lima; BERNARDI, Maria Martha. Farmacologia aplicada à medicina veterinária. 6. ed. Rio de Janeiro: Guanabara Koogan, 2018.

PEREIRA, Flávio Cardoso. Crime organizado e sua infiltraçăo nas instituiçôes governamentais.Săo Paulo: Atlas, 2015.

POPE JÚNIOR, HarrisonG.; KATZ, DavidL. Psychiatric and medical effects of anabolic-androgenic steroid use. A controlled study of 160 athletes. Archives of General Psychiatry, 
v. 51, i.5, pp. 375-382, Autumn 1994. Disponível em: <http://dx.doi.org/10.1001/archpsyc.1994.03950050035004> Acesso em: 05 fev. 2018.

ROXIN, Claus; GRECO, Luís; LEITE, Alaor. Doping e direito penal. Săo Paulo: Atlas, 2011. SKÅRBERG, Kurt;NYBERG, Fred; ENGSTRÖM, Ingemar. Is There an Association between the Use of Anabolic-Androgenic Steroids and Criminality? European Addiction Research, v. 16, pp. 213-219, 2010. Disponível em: ‘http://dx.doi.org/10.1159/000320286〉. Acesso em: 05 mar. 2018.

SANTOS, Azenildo Moura. 0 mundo anabólico: análise do uso de esteroides anabólicos nos esportes. Barueri, SP: Editora Manole, 2003.

SILVA, Alessandra Santana. Doping: aspectos penais. Editora Lumen Juris. Rio de Janeiro, 1999.

SILVA, Kaytiany Galdino; LIMA, Rodrigo Maciel. Prevalência da utilizaçăo de anabolizantes pelos estudantes de Educaçăo Física na cidade de Campos dos Goytacazes. Vértices, v. 9, n. 1-3, jan./dez. 2007. Disponível em: 〈https://is.gd/dKpmx0〉 Acesso em: 14 mar. 2018.

TAVARES, Otávio. Doping: argumentos em discussăo. Movimento,Porto Alegre, v. 8, n. 1, pp. 41-55, jan./abr. 2002. Disponível em: 〈https://is.gd/7dt74h〉. Acesso em: 20 abr. 2018.

WILAIRAT, Adrian. Faster, higher, stronger? Federal efforts to criminalize anabolic steroids and steroid precursors. Journal of Health Care Law \& Policy, v. 8, i. 2, 2005. Disponível em: 〈http://digitalcommons.law.umaryland.edu/jhclp/vol8/iss2/9> Acesso em: 04 mar. 2018.

ZAFFARONI, Eugenio Raul; PIERANGELI, José Henrique. Manual de direito penal brasileiro. 7. ed., v. 1. Săo Paulo: RT, 2007. 